\title{
Preparation of pitch from pyrolized fuel oil by electron beam radiation and its melt-electrospinning property
}

\author{
Jin-Young Jung and Young-Seak Lee* \\ Department of Fine Chemical Engineering and Applied Chemistry, Chungnam National University, Daejeon 305-764, Korea
}

\section{Article Info}

Received 27 February 2014

Accepted 26 March 2014

*Corresponding Author

E-mail: youngslee@cnu.ac.kr Tel: $+82-42-821-7007$

\section{Open Access}

DOI: http://dx.doi.org/

10.5714/CL.2014.15.2.129

This is an Open Access article distributed under the terms of the Creative Commons Attribution Non-Commercial License (http://creativecommons.org/licenses/ by-nc/3.0/) which permits unrestricted non-commercial use, distribution, and reproduction in any medium, provided the original work is properly cited.

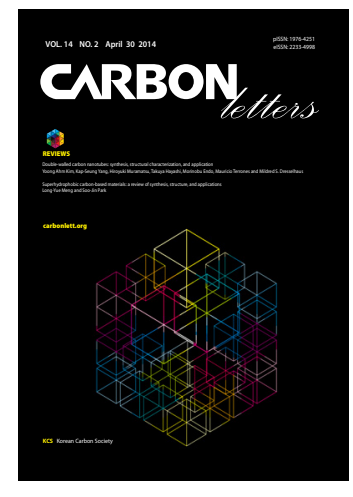

http://carbonlett.org

pISSN: 1976-4251

elSSN: 2233-4998

Copyright $\odot$ Korean Carbon Society

\begin{abstract}
Spinnable pitch for melt-electrospinning was obtained from pyrolized fuel oil by electron beam (E-beam) radiation treatment. The modified pitch was characterized by measuring its elemental composition, softening point, viscosity, molecular weight, and spinnability. The softening point and viscosity properties of the modified pitch were influenced by reforming types (heat or E-beam radiation treatment) and the use of a catalyst. The softening point and molecular weight were increased in proportion to absorbed doses of E-beam radiation and added $\mathrm{AlCl}_{3}$ due to the formation of pitch by free radical polymerization. The range of the molecular weight distribution of the modified pitch becomes narrow with better spinning owing to the generated aromatic compounds with similar molecular weight. The diameter of melt-electrospun pitch fibers under applied power of $20 \mathrm{kV}$ decreased $53 \%(4.7 \pm 0.9 \mu \mathrm{m})$ compared to that of melt-spun pitch fibers $(10.2 \pm 2.8 \mu \mathrm{m})$. It is found that E-beam treatment for reforming could be a promising method in terms of time-savings and cost-effectiveness, and the melt-electrospinning method is suitable for the preparation of thinner fibers than those obtained with the conventional melt-spinning method.
\end{abstract}

Key words: pitch, carbon fibers, melt-electrospinning, heat treatment, pyrolized fuel oil, electron beam radiation

\section{Introduction}

In recent years, carbon fibers (CFs) have gained recognition as promising materials in a variety of applications, such as automobile, aerospace, and construction industries as well as in general engineering [1,2]. The interest in CFs lies in their high strength, dimensional stability, high stiffness, and low coefficient of thermal expansion [3]. They can be produced from various raw materials such as polyacrylonitrile (PAN), rayon, resins, and pitches [4]. Even though demand for PAN-based CFs has continuously increased, they have many limitations related to high cost and low productivity [5]. On the other hand, pitch-based CFs have advantages in terms of low cost and environment concerns because the precursor materials are wood, oil from distillation of coal, and bottom oil from distillation of petroleum $[6,7]$. Also, pitch-based CFs have a better elastic modulus and thermal conductivity than those of PAN-based CFs [8-10]. Pitch-based CFs can be classified as follows: high performance CFs (HPCF) and general purpose CFs (GPCF). HPCF are used for high-tech performance applications on the basis of their excellent tensile strength, modulus, and thermal behavior. In terms of mass production, however, HPCF are quite expensive and their range of applications is limited to specific areas [11]. GPCF possess modest properties and can be produced on a large scale because of their relatively low price and wide range of applications compared to HPCF [12]. Therefore, the production of isotropic pitch-based CFs has gradually increased for the purpose of satisfying increasing demand.

Fluidized catalytic cracker decant oil and pyrolized fuel oil (PFO) with low sulfur, low insoluble components, and a high poly-aromatization degree have received attention as appro- 
priate petroleum based precursor materials of GPCF and needle cokes [13-15]. Reforming entails a series of reactions whereby volatile components and gas are evaporated from raw materials, and activated molecules as generated free radicals simultaneously go through cyclization, aromatization, and poly-condensation. Reformed pitches are generally obtained by thermal polymerization (heat soaking), which increases the cost owing to soaking time [16,17]. Using catalysts for polymerizing aromatic hydrocarbons, such as $\mathrm{AlCl}_{3}$ and $\mathrm{HF}-\mathrm{BF}_{3}$, can diminish not only soaking time but also reforming temperature [18]. Although the use of $\mathrm{HF}-\mathrm{BF}_{3}$ provides easier removal by distillation, the use of $\mathrm{AlCl}_{3}$ is more cost-effective than $\mathrm{BF}_{3}$, which requires larger facilities and fabrication costs $[18,19]$.

Electron beam (E-beam) radiation has been extensively applied in polymer modification, such as cross-linking, curing, and grafting, due to optical transparency of the system and the absence of need of a chemical/photochemical initiator [20]. Like other polymerization methods, E-beam triggered polymerization proceeds in a fast-paced manner with the generation of free radicals. Furthermore, the molecular weight of the polymer is greatly increased when free radical termination has been minimized [21]. Reforming of petroleum-based precursor materials by E-beam radiation has not been reported.

One way to improve the properties and functionality of $\mathrm{CFs}$ is to decrease the fiber diameter. Preparing thin pitch-based CFs by the conventional melt-spinning method is difficult due to a broad molecular weight distribution, which impedes continuous spinning. To address this problem, various studies on rheological behavior have been conducted according to the reforming conditions of raw material pitch with many additives [22]. In addition, introduction of an electro-spinning method, which has been widely used for PAN polymers, can yield thin fibers even with a broad molecular weight distribution [23]. However, only a few studies have been carried out on the preparation of pitch fibers by melt-electrospinning methods.

In this study, we prepared reformed pitch from PFO by E-beam radiation to obtain thin pitch fibers with a melt-electrospinning method. The effect of E-beam treatment with a catalyst on the spinnability of the modified pitch was investigated from an elemental analysis and through investigation of the softening point, molecular weight, viscosity, and fiber diameter.

\section{Experimental}

\subsection{Materials}

The precursor of the pitch used in this work was PFO, supplied by the GS Caltex Refinery Company in Korea. Aluminum chloride (98\%, Junsei Chemical, Japan) was used as a catalyst for reforming.

\subsection{Reforming of PFO}

The pitch was obtained from PFO through a recently reported procedure that includes subsequent distillation and thermal treatment [24]. The spinnable isotropic pitch was prepared through two-stage thermal condensation of the PFO.
Table 1. Reforming conditions of pitches

\begin{tabular}{ccccc} 
& \multicolumn{4}{c}{ Reforming conditions } \\
\cline { 2 - 5 } Samples & Temp. $\left({ }^{\circ} \mathrm{C}\right)$ & $\begin{array}{c}\text { Absorbed } \\
\text { dose } \\
(\mathrm{kGy})\end{array}$ & $\begin{array}{c}\text { Energy } \\
(\mathrm{MeV})\end{array}$ & $\mathrm{AlCl}_{3}(\mathrm{~g})$ \\
\hline HP & 350 & - & - & - \\
EP50 & 270 & 10 & 2.5 & - \\
EP200 & 270 & 50 & 2.5 & - \\
EPA200 & 270 & 50 & 2.5 & 0.5 \\
\hline
\end{tabular}

${ }^{1)} \mathrm{HP}$ : heat treated pitch, ${ }^{2)} \mathrm{EP} 50$ : E-beam treated pitch by $10 \mathrm{kGy}$ ${ }^{3)} \mathrm{EP} 200$ : E-beam treated pitch by $50 \mathrm{kGy}$,

${ }^{4)} \mathrm{EPA} 200$ : E-beam treated pitch to be included with $\mathrm{AICl} 3$ by $50 \mathrm{kGy}$

The procedure involved heating approximately $500 \mathrm{~g}$ of the PFO from room temperature to $350^{\circ} \mathrm{C}$ at a heating rate of $2^{\circ} \mathrm{C} / \mathrm{min}$ under a $2 \mathrm{~L} / \mathrm{min}$ nitrogen flow with a $200 \mathrm{rpm}$ impelling rate. The sample was then maintained at $350^{\circ} \mathrm{C}$ for $2 \mathrm{~h}$ and subsequently naturally cooled. For the E-beam treatment, $5 \mathrm{~g}$ of PFO and PFO incorporating $10 \mathrm{wt} \% \mathrm{AlCl}_{3}$ were poured into respective glass sample bottles. Nitrogen was filled in the sample bottles for 2 min to remove oxygen. The sample bottles were then immediately sealed with lids, and placed on a tray for E-beam radiation. E-beam radiation was carried out at $10 \mathrm{kGy}$ and $50 \mathrm{kGy}$. As shown in Table 1, the prepared samples were labeled according to the treatment conditions as HP, EP50, EP200, and EPA200, respectively.

\subsection{Melt-electrospinning of reformed pitch}

The pitch fibers were prepared from the reformed pitch through a novel melt-electrospinning procedure [25]. In this method, a glass-syringe apparatus with a $20 \mathrm{~g}$ sample capacity was used to extrude the precursors through a mono-hole spinneret with a diameter of $0.1 \mathrm{~mm}$. The following meltelectrospinning conditions were maintained throughout the process: applied voltage: $0-20 \mathrm{kV}$, tip to collector distance: $20 \mathrm{~cm}$, syringe pump rate: $1.0 \mathrm{~mL} / \mathrm{h}$ and collector speed: $1500 \mathrm{rpm}$. The spinning temperature of the pitch for meltelectrospinning was $50-80^{\circ} \mathrm{C}$ higher than the softening point of the spinnable pitch.

\subsection{Characterizations}

Elemental analysis of the PFO and the reformed pitch was performed using an elemental analyzer (EA1110, CE Instrument, Italy). The softening point and molecular weight distribution were investigated using a softening point apparatus (FP90, Mettler, Switzerland) and matrix-assisted desorption ionization (MALDI)-TOF (Bruker Daltonics, Germany), respectively. A viscometer (Brookfileld DV-II, Germany) was used to measure the viscosity according to the temperature. To measure the diameter of the pitch fiber obtained from modified pitches, scanning electron microscope (SEM) images were obtained using a field emission SEM (S-5500, Hitachi, Japan). 
Table 2. Characteristics of PFO and reformed pitches

\begin{tabular}{|c|c|c|c|c|c|c|}
\hline \multicolumn{2}{|c|}{ Properties } & \multirow{2}{*}{ PFO } & \multicolumn{4}{|c|}{ Reformed pitch } \\
\hline & & & HP & EP50 & EP200 & EPA200 \\
\hline \multirow{5}{*}{$\begin{array}{l}\text { Elemental analy- } \\
\text { sis (wt \%) }\end{array}$} & $\mathrm{C}$ & 90.59 & 93.42 & 92.97 & 93.28 & 93.53 \\
\hline & $\mathrm{H}$ & 6.18 & 4.99 & 5.27 & 5.06 & 5.17 \\
\hline & $\mathrm{N}$ & 2.19 & 0.98 & 1.1 & 1.02 & 0.91 \\
\hline & $\mathrm{O}$ & 0.94 & 0.53 & 0.57 & 0.55 & 0.49 \\
\hline & $\mathrm{S}$ & 0.1 & 0.08 & 0.09 & 0.09 & 0.08 \\
\hline \multicolumn{2}{|c|}{ Atomic mole ratio $(\mathrm{C} / \mathrm{H})$} & 1.09 & 1.32 & 1.26 & 1.28 & 1.31 \\
\hline \multicolumn{2}{|c|}{ Density $\left(\mathrm{g} / \mathrm{cm}^{3}\right)$} & 1.07 & 1.13 & 1.09 & 1.11 & 1.14 \\
\hline \multicolumn{2}{|c|}{ Softening point $\left({ }^{\circ} \mathrm{C}\right)$} & - & 175.4 & 119.2 & 153.3 & 181.3 \\
\hline \multicolumn{2}{|c|}{$\mathrm{Mz}_{\mathrm{z}}^{\mathrm{a}}$} & 1045 & 1302 & 1243 & 1287 & 1362 \\
\hline
\end{tabular}

PFO: pyrolized fuel oil.

${ }^{\text {a) }}$ Average molecular weight.

\section{Results and Discussion}

\subsection{Elemental analysis of samples}

The characteristics of PFO and reformed pitch are summarized in Table 2. Nitrogen, oxygen, and sulfur content decreased compared to increased carbon content according to heat and E-beam treatment. In particular, the sulfur content of PFO is relatively very low $(0.1 \mathrm{wt} \%)$ compared to commercial A-20 pitch (2.4 wt\%), and it is thereby found that PFO is an appropriate precursor of carbon materials [26]. It has been also observed that the atomic mole ratio $(\mathrm{C} / \mathrm{H})$ increased from 1.09 to 1.32 . This is attributable to oxygen and hydrogen being converted into $\mathrm{CO}_{2}, \mathrm{CO}$, and $\mathrm{CH}_{4}$, and volatilized during pyrolysis reaction of high molecular weight components. Low molecular weight components are simultaneously converted into aromatic compounds by poly-condensation [27]. The density of reformed pitch increased from 1.07 to 1.14 due to the removal of gas, which was converted from low molecular weight components by heat and E-beam treatment. The removal of low molecular weight components induced the disordered phase of isotropic pitch to become increasingly ordered. In addition, the hydrogen content of EPA200 is smaller than that of $\mathrm{HP}$ and $\mathrm{EP} 200$, which confirms that $\mathrm{AlCl}_{3}$ hinders dehydrogenative polymerization. This is consistent with results presented previously by other authors [28].

\subsection{Molecular weight distribution property of samples}

Table 2 indicates the average molecular weight $\left(\mathrm{M}_{\mathrm{z}}\right)$ of PFO (Fig. 1a), heat treated pitch (Fig. 1b), and E-beam treated pitch (Figs. 1c-e) calculated by the following formula:

$$
\mathrm{Mz}=\sum \mathrm{N}_{\mathrm{i}} \mathrm{M}_{\mathrm{i}}^{3} / \sum \mathrm{N}_{\mathrm{i}} \mathrm{M}_{\mathrm{i}}^{2}
$$

where $\mathrm{N}_{\mathrm{i}}$ is the molecular weight and $\mathrm{M}_{\mathrm{i}}$ is the absolute intensity of molecular weight. It is observed that the $M_{z}$ value of the prepared samples increased in the order of PFO, EP50, EP200, HP, and EPA200, and it could therefore be clearly found that the molecular weight increased relative largely according to heat and E-beam radiation treatment. The results indicated that the low molecular weight components were converted to gas through heat and E-beam radiation treatment, as shown in the results of the elemental analysis. The molecular weight of the E-beam treated pitch proportionally increased with increasing absorbed doses of E-beam radiation, as shown in EP50 and EP200. In this sense, it presumed that the formation of pitch by free radical polymerization involves several elementary reaction steps: radical formation/initiation, free radical propagation, and transfer of free radical activity to various molecules [29]. Also, the addition of $\mathrm{AlCl}_{3}$ as a catalyst leads to increased molecular weight, as confirmed in EP200 and EPA200. The molecular growth in petroleum residue could be accelerated by using $\mathrm{AlCl}_{3}$ in heat treatment. From our study, it was also confirms that $\mathrm{AlCl}_{3}$ play a catalytic role in molecular growth in E-beam radiation treatment as well as heat treatment, in agreement with previous results [30]. The molecular weight distribution of PFO was from 52.3 to 982.4, and that of HP, EP50, EP200, and EPA200 were 192.4 787.8, 172.2 832.5, 163.2 817.2, and 203.3 742.5, respectively, as shown in the MALDI spectrum. The range of the molecular weight distribution becomes narrow in proportion to absorbed doses of E-beam radiation and added $\mathrm{AlCl}_{3}$. This is because low molecular weight components were converted to gas or polymerized with other molecules, and high molecular weight components with very low absorbed intensity simultaneously decreased through this treatment. Therefore, the increase of molecular weight was not remarkable not only by heat treatment but also with E-beam radiation treatment (Table 2). Molecular growth and a narrow molecular weight distribution indicate that aromatic compounds with similar molecular weight were formed during heat and E-beam reforming. Also, 

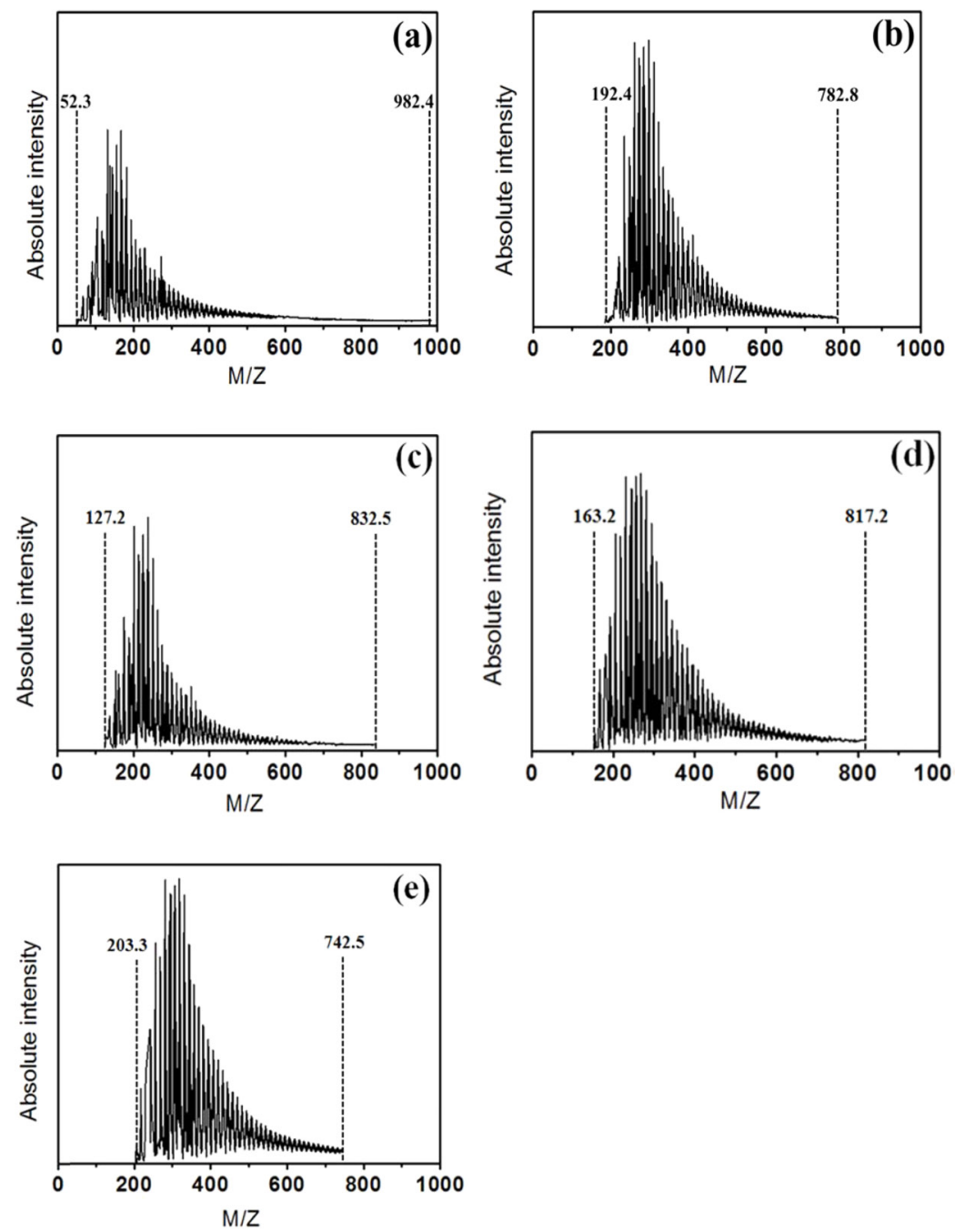

Fig. 1. Matrix-assisted desorption ionization spectra of (a) pyrolized fuel oil, (b) HP, (c) EP50, (d) EP200, (e) EPA200.

it had a eutectic property, which means fibers diameter could be uniform with continuous spinnability. Pitch with low molecular weight generally has poor spinnability, and pitch with wide molecular weight distribution results in non-uniform fiber diameter. For this reason, it is necessary to incorporate components with low insolubility and uniform viscosity at the melt-spinning temperature, as they are associated with a narrow molecular weight distribution and appropriate molecular weight.

\subsection{Softening point and viscosity properties of reformed pitch}

The optimum spinning temperature of reformed pitch is considered to be dependent upon the softening point and viscosity property. As shown in Table 2, the softening points of the precursor pitch increased in proportion to absorbed doses of E-beam radiation and added $\mathrm{AlCl}_{3}$, revealing a similar trend for the molecular weight of the reformed pitch. In particular, the softening point of EPA200 sample was much higher than that of HP. This indicates that appropriate E-

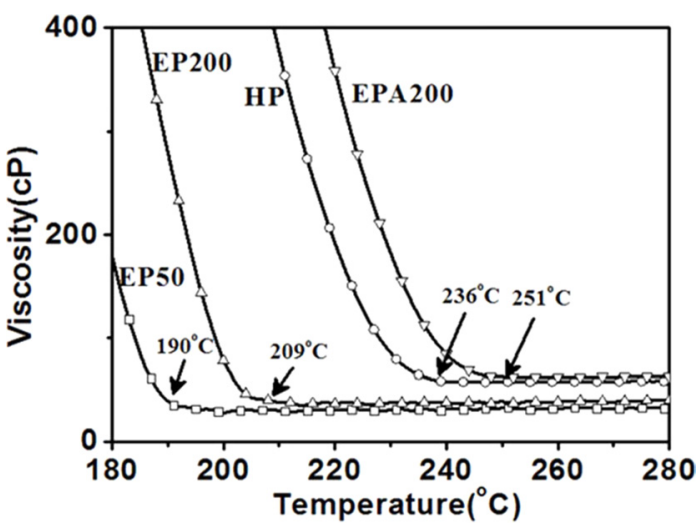

Fig. 2. Viscosity property of reformed pitches according to temperature.

beam radiation with a catalyst could result in higher softening points in comparison with heat treatment. Berrueco et al. [31] reported that the optimum spinning temperature of pitch 
is approximately $50 \sim 80^{\circ} \mathrm{C}$ higher than the softening point. In Fig. 2, the viscosity of the reformed pitch is presented according to temperature. Initially, the viscosity rapidly decreased with increasing temperature, and then low viscosity is maintained after a certain temperature. The viscosity thus has a plateau. The viscosity having a plateau of HP, EP50, EP200, and EPA200 were 59.3, 29.7, 36.6, and $63.8 \mathrm{cP}$, which initiated at $236,190,209$, and $251^{\circ} \mathrm{C}$, respectively. The temperature range for the plateau of viscosity was included in the optimum spinning temperature [31].

Melt-electrospinning was hence performed at the initial temperature of the viscosity plateau. Kim et al. [32] reported that as-spun fibers were obtained below $100 \mathrm{cP}$ in electrospinning. In our study, the viscosities of all reformed pitch were below $100 \mathrm{cP}$, at which level they were expected to have good spinnability. EPA200 reformed by E-beam radiation and with the addition of $\mathrm{AlCl}_{3}$ was better spun compared to EP50 and EP200. The results showed that the molecular weight distribution and viscosity are both prominent factors in meltelectrospinning. When the molecular weight distribution was relatively wide, the spinnability of the pitch was affected due to the difference in flowability between low and high molecular weight components. The wide molecular weight distribution consequently adversely affected the spinnability. Additionally, change of viscosity according to different reforming methods (heat/E-beam radiation treatment, use of a catalyst) affects fiberizaton. Generally, the flowability of molten pitch for electro-spinning remarkably decreased due to minimized surface tension at a high viscosity condition. On the contrary, it is difficult to form desired fiber shape at low viscosity because of entanglement of polymer chains. Given these findings, the EPA200 sample, which possesses a relatively narrow molecular weight distribution and appropriate viscosity (approximately $60 \mathrm{cP}$ ) exhibited the best spinnability in the conditions employed in this study.

\subsection{Evaluation of fiber diameter}

SEM images of melt-electrospun pitch fibers prepared from the EPA200 sample according to applied voltage (0-20 $\mathrm{kV}$ ) are provided in Fig. 3. It is well known that the diameter of pitch fibers obtained by the conventional melt-spinning method are in a range of 10-30 $\mu \mathrm{m}$ [31]. Similarly, the diameter of fibers without applied voltage (only melt-spinning) were approximately $10 \mu \mathrm{m}$, corresponding with the aforementioned range of diameter. As the applied voltage was increased from $5 \mathrm{kV}$ to $20 \mathrm{kV}$, the fiber diameter conversely decreased from $17 \%$ to $53 \%$ in comparison with $10 \mu \mathrm{m}$ pitch fibers. It is suggested that die-swelling occurred at the end of the capillary tip due to surface tension during electro-spinning. While electric charges were derived on the capillary tip, and minimized pitch was sprayed to form the non-woven fiber unlikely the behavior of melt-spinning. The diameter and distribution of as-spun pitch fibers are shown in Fig. 4. The average diameter of melt-spun fibers without applied voltage was $10.2 \pm 2.8 \mu \mathrm{m}$, and these fibers had a wide distribution compared to melt electro-spun fibers according to the applied voltage $(5 \mathrm{kV}: 8.5 \pm 1.7 \mu \mathrm{m}, 10 \mathrm{kV}: 6.9 \pm 1.3 \mu \mathrm{m}, 20 \mathrm{kV}: 4.7$ $\pm 0.9 \mu \mathrm{m})$, as observed in SEM images. It is presumed that
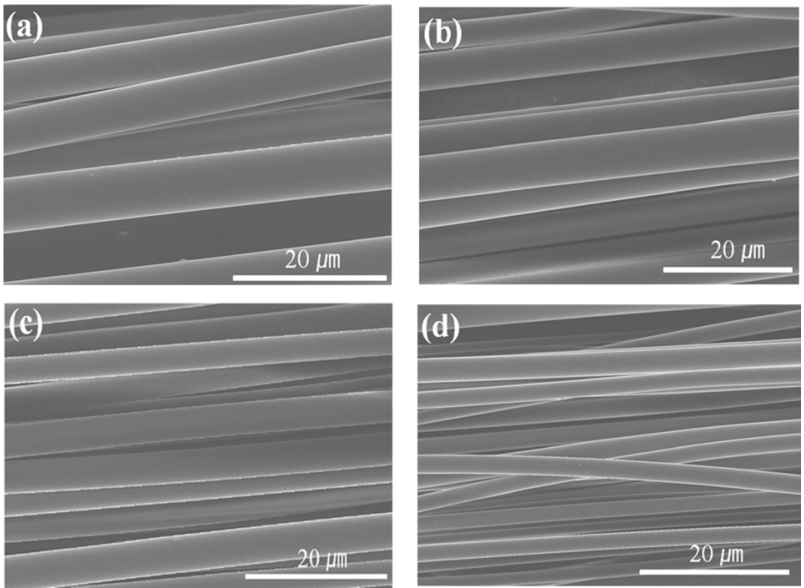

Fig. 3. Scanning electron microscope images of (a) 0 kV-EPA200, (b) 5 kV-EPA200, (c) 10 kV-EPA200, (d) 20 kV-EPA200.

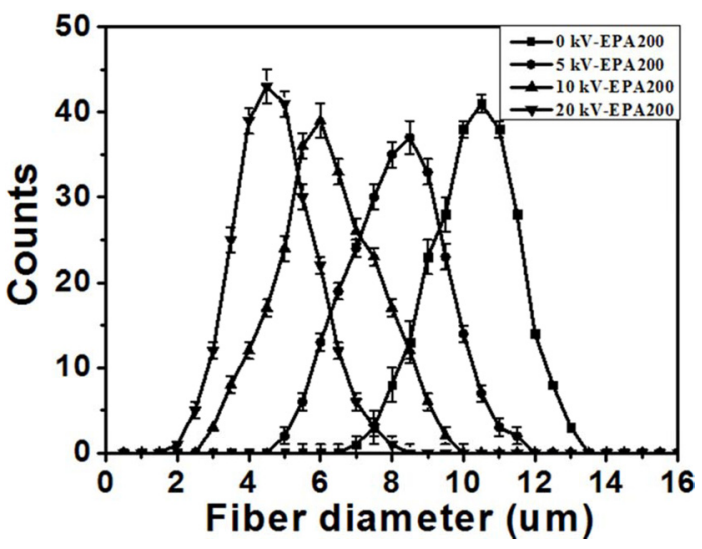

Fig. 4. Fiber diameter distribution of pitch fibers according to the meltelectrospinning conditions.

relatively thin and uniform pitch fibers can be obtained by using melt-electrospinning under high applied voltage due to electric charges derived on the molten pitch.

\section{Conclusions}

In this study, reformed pitch was obtained from PFO by Ebeam treatment, and its melt-electrospinning properties were investigated. The softening point and molecular weight increased by E-beam radiation and heat treatment with the addition of $\mathrm{AlCl}_{3}$ due to modification of the pitch by free radical polymerization. It was found that the range of weight distribution becomes narrow because of the generation of aromatic compounds with similar molecular weight, and thus the modified pitch can have good spinnability with uniform diameter in continuity. The optimum viscosity was approximately $60 \mathrm{cP}$ for melt-electrospinning of E-beam and $\mathrm{AlCl}_{3}$ treated pitch, and the diameter of the melt-electrospun pitch fibers decreased from $17 \%$ to $54 \%$ $(4.7 \pm 0.9 \mu \mathrm{m})$ in comparison with melt-spun fibers $(10.2 \pm 2.8$ $\mu \mathrm{m})$. In conclusion, thin and uniform pitch fibers were prepared 
by melt-electrospinning under applied power of $20 \mathrm{kV}$. Overall, spinnable isotropic pitch or GPCF could be readily obtained from PFO by using E-beam reforming, which is a promising method in terms of time-savings and cost-effectiveness.

\section{Acknowledgement}

This research was supported by the National Research Foundation of Korea (NRF) funded by the Ministry of Science, ICT \& Future Planning (No. 2013M2A2A6043697).

\section{References}

[1] Kim JG, Im JS, Bae TS, Kim JH, Lee YS. The electrochemica behavior of an enzyme biosensor electrode using an oxyfluorinated pitch-based carbon. J Ind Eng Chem, 19, 94 (2013). http://dx.doi. org/10.1016/j.jiec.2012.07.008

[2] Kim BJ, Lee YS, Park SJ. Novel porous carbons synthesized from polymeric precursors for hydrogen storage. Int J Hydrogen Energy, 33, 2254 (2008). http://dx.doi.org/10.1016/j.ijhydene.2008.02.019.

[3] Yang Q, Liu J, Li S, Wang F, Wu T. Fabrication and mechanical properties of $\mathrm{Cu}$-coatedwoven carbon fibers reinforced aluminum alloy composite. Mater Des, 57, 442 (2014). http://dx.doi. org/10.1016/j.matdes.2013.12.064.

[4] Naito K, Tanaka Y, Yang JM, Kagawa Y. Tensile properties of ultrahigh strength PAN-based, ultrahigh modulus pitch-based and high ductility pitch-based carbon fibers. Carbon, 46, 189 (2008). http://dx.doi.org/10.1016/j.carbon.2007.11.001

[5] Yusof N, Ismail AF. Post spinning and pyrolysis processes of polyacrylonitrile (PAN)-based carbon fiber and activated carbon fiber: a review. J Anal Appl Pyrolysis, 93, 1 (2012). http://dx.doi org/10.1016/j.jaap.2011.10.001.

[6] Heo GY, Yoo YJ, Park SJ. Effect of carbonization temperature on electrical conductivity of carbon papers prepared from petroleum pitch-coated glass fibers. J Ind Eng Chem, 19, 1040 (2013). http:// dx.doi.org/10.1016/j.jiec.2012.11.028.

[7] Mora E, Blanco C, Prada V, Santamaría R, Granda M, Menéndez R. A study of pitch-based precursors for general purpose carbon fibres. Carbon, 40, 2719 (2002). http://dx.doi.org/10.1016/S00086223(02)00185-9.

[8] Greene ML, Schwartz RW, Treleaven JW. Short residence time graphitization of mesophase pitch-based carbon fibers. Carbon, $\mathbf{4 0}$, 1217 (2002). http://dx.doi.org/10.1016/S0008-6223(01)00301-3.

[9] Watanabe F, Ishida S, Korai Y, Mochida I, Kato I, Sakai Y, Kamatsu M. Pitch-based carbon fiber of high compressive strength prepared from synthetic isotropic pitch containing mesophase spheres. Carbon, 37, 961 (1999). http://dx.doi.org/10.1016/S00086223(98)00251-6.

[10] Adams PM, Katzman HA, Rellick GS, Stupian GW. Characterization of high thermal conductivity carbon fibers and a selfreinforced graphite panel. Carbon, 36, 233 (1998). http://dx.doi org/10.1016/S0008-6223(97)00189-9.

[11] Maeda T, Ming Zeng S, Tokumitsu K, mondori J, Mochida I. Preparation of isotropic pitch precursors for general purpose carbon fibers (GPCF) by air blowing. I. Preparation of spinnable isotropic pitch precursor from coal tar by air blowing. Carbon, 31, 407 (1993). http://dx.doi.org/10.1016/0008-6223(93)90127-V
[12] Díez N, Álvarez P, Santamaría R, Blanco C, Menéndez R, Granda M. Optimisation of the melt-spinning of anthracene oil-based pitch for isotropic carbon fibre preparation. Fuel Process Technol, 93, 99 (2012). http://dx.doi.org/10.1016/j.fuproc.2011.09.016.

[13] Mochida I, Oyama T, Korai Y. Improvements to needle-coke quality by pressure reductions from a tube reactor. Carbon, 26, 57 (1988). http://dx.doi.org/10.1016/0008-6223(88)90009-7.

[14] Oh SM, Yoon SH, Lee GD, Park YD. Effects of pressurized pretreatment on the preparation of mesophase pitch. Carbon, 29, 1009 (1991). http://dx.doi.org/10.1016/0008-6223(91)90180-Q

[15] Park YD, Mochida I. A two-stage preparation of mesophase pitch from the vacuum residue of FCC decant oil. Carbon, 27, 925 (1989). http://dx.doi.org/10.1016/0008-6223(89)90043-2.

[16] Lewis IC. Thermal polymerization of aromatic hydrocarbons. Carbon, 18, 191 (1980). http://dx.doi.org/10.1016/0008-6223(80)90060-3.

[17] Menéndez R, Granda M, Fernández JJ, Figueiras A, Bermejo J, Bonhomme J, Belzunce J. Influence of pitch air-blowing and thermal treatment on the microstructure and mechanical properties of carbon/carbon composites. J Microsc, 185, 145 (1997). http:// dx.doi.org/10.1046/j.1365-2818.1997.d01-608.x.

[18] Mochida I, Shimizu K, Korai Y, Otsuka H, Fujiyama S. Structure and carbonization properties of pitches produced catalytically from aromatic hydrocarbons with $\mathrm{HF} / \mathrm{BF}_{3}$. Carbon, 26, 843 (1988). http://dx.doi.org/10.1016/0008-6223(88)90108-X

[19] Mochida I, Yoon SH, Korai Y, Kanno K, Sakai Y, Komatsu M. Carbon-fibers from aromatic-hydrocarbons. Chem Tech, 25, 29 (1995).

[20] Vautard F, Ozcan S, Poland L, Nardin M, Meyer H. Influence of thermal history on the mechanical properties of carbon fiber-acrylate composites cured by electron beam and thermal processes. Composites A, 45, 162 (2013). http://dx.doi.org/10.1016/j.compositesa.2012.08.025.

[21] Schlemmer B, Bandari R, Rosenkranz L, Buchmeiser MR. Electron beam triggered, free radical polymerization-derived monolithic capillary columns for high-performance liquid chromatography. J Chromatogr A, 1216, 2664 (2009). http://dx.doi.org/10.1016/j. chroma.2008.09.003.

[22] Kunowsky M, Marco-Lozar JP, Cazorla-Amorós D, Linares-Solano A. Scale-up activation of carbon fibres for hydrogen storage. Int J Hydrogen Energy, 35, 2393 (2010). http://dx.doi.org/10.1016/j. ijhydene.2009.12.151.

[23] Dalton PD, Grafahrend D, Klinkhammer K, Klee D, Möller M. Electrospinning of polymer melts: phenomenological observations. Polymer, 48, 6823 (2007). http://dx.doi.org/10.1016/j.polymer.2007.09.037.

[24] Lee YS, Basova YV, Edie DD, Reid LK, Newcombe SR, Ryu SK. Preparation and characterization of trilobal activated carbon fibers. Carbon, 41, 2573 (2003). http://dx.doi.org/10.1016/S00086223(03)00376-2.

[25] Kim JH, Lee SH, Lee YS. Preparation of pitch for melt-electrospinning from naphtha cracking bottom oil. Appl Chem Eng, 24 402 (2013).

[26] Hwang JS, Lee CH, Cho KH, Kim MS, Kim CJ, Ryu SK, Rhee BS. Preparation of anisotropic/isotropic pitches from NCC-PFO. J Korean Inst Chem Eng, 33, 551 (1995).

[27] In SJ, Ryu SK, Rhee BS. Effect of stirring speed and $\mathrm{N}_{2}$-blowing rate on mesophase formation from naptha tar pitch. J Korean Inst Chem Eng, 27, 291 (1989).

[28] Mochida I, Kudo K, Fukuda N, Takeshita K, Takahashi R. Car- 
bonization of pitches-IV: Carbonization of polycyclic aromatic hydrocarbons under the presence of aluminum chloride catalyst. Carbon, 13, 135 (1975). http://dx.doi.org/10.1016/00086223(75)90270-5.

[29] Botman JIM, Derksen ATAM, van Herk AM, Jung M, Kuchta FD, Manders LG, Timmermans CJ, de Voigt MJA. A linear accelerator as a tool for investigations into free radical polymerization kinetics and mechanisms by means of pulsed electron beam polymerization. Nucl Instrum Methods Phys Res B, 139, 490 (1998). http:// dx.doi.org/10.1016/S0168-583X(97)00948-8.
[30] Fernández AL, Granda M, Bermejo J, Menéndez R. Catalytic polymerization of anthracene oil with aluminium trichloride. Carbon, 37, 1247 (1999). http://dx.doi.org/10.1016/S0008-6223(98)00321-2.

[31] Berrueco C, Álvarez P, Díez N, Granda M, Menéndez R, Blanco C, Santamaria R, Millan M. Characterisation and feasibility as carbon fibre precursors of isotropic pitches derived from anthracene oil Fuel, 101, 9 (2012). http://dx.doi.org/10.1016/j.fuel.2011.10.005.

[32] Kim CN, Xing ZC, Baek JY, Bae HS, Kang IK. Preparation of antibacterial nanofibrous PMMA nonwoven fabrics. Polymer (Korea), 33, 429 (2009). 